\title{
Etnomedisin Obat Hipertensi di Kabupaten Kebumen
}

\author{
Husnul Khuluq $^{1 *}$, Naelaz Zukhruf ${ }^{2,}$ Tri Cahyani ${ }^{3}$, Alife Stefani ${ }^{4}$, Laely \\ Fitriyati $^{5}$, Khobirotul Majidah ${ }^{6}$, Beti Dwi ${ }^{7}$, Jesica Yuliana ${ }^{8}$ \\ ${ }^{1,2}$ Dosen Prodi Farmasi Stikes Muhammadiyah Gombong \\ Jl. Yos Sudarso No. 461 Gombong, Kebumen, Jawa Tengah, Indonesia \\ ${ }_{3,4,5,6,7,8}$ Mahasiswa Prodi S1 Farmasi Program Sarjana Stikes Muhammadiyah \\ Gombong \\ *Email: ${ }^{1}$ Husnul66@ unlidrive,com; ${ }^{2}$ naela.zukhruf18@ gmail.com; \\ ${ }^{3}$ tricahyaniapt@gmail.com; ${ }^{4}$ alifestefani16@gmail.com; ${ }^{5}$ laeli.fitriyati.lf@gmail; \\ jidahkhobir@gmail.com; ${ }^{6}$ betidwin05@gmail.com; ${ }^{8}$ jesikay25@gmail.com
}

Tanggal Submisi: 12 Mei 2021; Tanggal Penerimaan: 21 April 2021

\begin{abstract}
ABSTRAK
Hipertensi adalah salah satu faktor terpenting yang bertanggung jawab atas penyakit kardiovaskular di seluruh dunia. Produk herbal dan terapi herbal alternatif memainkan peran penting dalam mengurangi hipertensi. Tujuan dari penelitian ini memberikan informasi etnomedisin secara kualitatif maupun kuantitatif pada tanaman obat yang digunakan masyarakat lokal Kebumen untuk pengobatan hipertensi . Sebanyak 250 responden dari 5 Kecamatan yang diperoleh dengan cara snow ball kemudian diwawancarai secara semi-terstruktur dan pertanyaan dengan kuesioner. Didapat data 20 spesies dari 15 famili yang digunakan untuk pengobatan hipertensi. Bagian Tanaman yang paling banyak digunakan adalah daun ( 52,3\%), sebagian besar disiapkan dengan cara direbus (65\%), Cara menggunakan sebagian besar diminum (71,42\%), Dalam penelitian ini data asli dibandingkan dengan jurnal nasional dan internasional untuk membandingkan penggunaan obat dan mendapatkan beberapa spesies tanaman baru. Satu spesies tanaman obat belum ditemukan literatur ilmiah sebagai obat antihipertensi, 5 spesies sudah pernah di uji klinik sementara 14 spesies sudah diuji preklinik dengan hewan uji atau in vitro. Aktivitas fitokimia yang berbeda dari tanaman antihipertensi juga dilaporkan dari literatur.
\end{abstract}

Kata kunci: Etnofarmakologi hipertensi, Etnomedisin hipertensi, Obat herbal hipertensi

\begin{abstract}
One of the most major factors responsible for cardiovascular disease worldwide is hypertension. In reducing hypertension, herbal products and alternate herbal therapies play a significant role. The aim of this study is to provide both qualitative and quantitative information on ethnomedicine for the treatment of hypertension in medicinal plants used by local Kebumen communities. A total of 250 respondents
\end{abstract}


were then interviewed semi-structured and questioned by a questionnaire from 5 Districts collected by snowball technique. Data from 20 species in 15 families that are used for the treatment of hypertension. Leaf were the most commonly used component of the plant (52.3 percent), most of it was prepared by boiling (65 percent), most of the way to use it was drunk (71.42 percent ). Compare medicinal uses and get a few new varieties of plants. One species of medicinal plant has not been identified as an antihypertensive drug in scientific literature, five species have been tested in clinical trials, and 14 species have been pre-clinically or in vitro tested with laboratory animals. The numerous phytochemical activities of antihypertensive plants have also been recorded in the literature.

Keyw ords: Hypertension ethnopharmacology, Hypertension ethnomedicin, Hypertension herbal medicine

ISSN 1979-7621 (Print). ISSN 2620-7761 (Online).

DOI : $10.23917 /$ jk.v14i1.13898

\section{PENDAHULUAN}

Etnobotani secara harfiah memiliki arti yaitu ilmu yang mengkaji tentang pengetahuan botani yang dimiliki oleh masyarakat lokal. Sedangkan etnobotani secara terminology berarti hubungan antara tanaman dengan kelompok atau etnis masyarakat tertentu (Tapundu et al., 2015). Etnomedisin merupakan salah satu cabang ilmu etnobotani yang mengungkapkan pengetahuan lokal berbagai etnis dalam menjaga kesehatannya. Secara empirik terlihat bahwa dalam pengobatan tradisional memanfaatkan tumbuhan maupun hewan, namun dilihat dari jumlah maupun frekuensi pemanfaatannya tumbuhan lebih banyak dimanfaatkan dibandingkan hewan. Hal tersebut mengakibatkan pengobatan tradisional identik dengan tumbuhan (E, 2017). Pengetahuan yang dimiliki masyarakat saat ini hanya sebatas pengetahuan turun temurun sebagai bentuk interaksi antara masyarakat dengan lingkungannya khususnya tumbuhan . Di negara Indonesia, sekalipun pelayanan kesehatan telah berkembang, jumlah masyarakat yang memanfaatkan pengobatan tradisional tetap tinggi (Eko Atmojo, 2015).

Hipertensi dikenal secara luas sebagai penyakit kardiovaskular. Diperkirakan telah menyebabkan $4.5 \%$ dari beban penyakit secara global, dan prevalensinya hampir sama besar di negara berkembang maupun di negara maju. Hipertensi merupakan salah satu faktor risiko utama gangguan jantung. Selain mengakibatkan gagal jantung, hipertensi dapat berakibat terjadinya gagal ginjal maupun penyakit serebrovaskular. Penyakit ini bertanggung jawab terhadap tingginya biaya pengobatan dikarenakan alasan tingginya angka kunjungan ke dokter, perawatan di rumah sakit dan / atau penggunaan obat jangka panjang (Kemenkes, 2006).

Penelitian ini bertujuan untuk mengetahui tanaman obat yang digunakan oleh masyarakat di kabupaten Kebumen sebagai obat hipertensi. Penelitian dilakukan dengan survey dan wawancara langsung. 


\section{METODE PENELITIAN}

Jenis penelitian yang digunakan yaitu dengan menggunakan metode kualitatif dengan teknik survei, wawancara semi terstruktur. Penggunaan metode kualitatif dalam penelitian ini dimaksudkan untuk mendeskripsikan pengetahuan masyarakat dengan pendekatan etnik (perspektif masyarakat).

Penentuan partisian/responden dilakukan dengan menggunakan teknik snowball sampling. Responden terdiri dari informan kunci dan informan umum, dimana informan kunci tersebut meliputi kepala desa, dukun, penjual jamu tradisional, dan petugas puskesmas bagian herbal. Sedangkan informan umum pada penelitian ini meliputi masyarakat yang mengetahui pemanfaatan herbal sebagai obat hipertensi dan menanam atau membudidayakan tanaman tersebut. Penentuan jumlah responden dihitung menggunakan rumus solvin.

Perhitungan responden/
partisipan dari masing-masing
kecamatan yaitu kecamatan Buayan, Ayah, Puring, Petanahan dan Sruweng dengan dasar perhitungan jumlah kepala keluarga didapat total sampel adalah 250 dari setiap kecamatan 50 orang. Dari setiap kecamatan diambil 5 desa untuk mewakili kemudian setiap desa diambil masing-masing 10 responden.

Pemilihan responden ini nantinya akan dipilih berdasarkan kriteria inklusi (masyarakat yang memilki pengetahuan terkait pemanfaatan herbal untuk hipertensi dan menanam atau membudidayakan tanaman tersebut) serta kriteria eksklusi (masrakat yang tidak memiliki pengetahuan terkait pemanfaatan tanaman herbal untuk hipertensi).

Penelitian ini dilaksanakan di lima kecamatan Kabupaten Kebumen antara lain Kecamatan Buayan, Sruweng, Ayah, Puring, dan Petanahan. Penelitian ini dilaksanakan selama kurang lebih 6 bulan, bermula dari studi pustaka dan pembuatan proposal penelitian hingga analisis data.

Alat yang digunakan yaitu kamera digital/ HP, mistar, spidol dan alat tulis, perekam suara, aplikasi android untuk mengetahui titik koordinat suatu tempat, gunting, plastik, koran. Bahan yang digunakan yaitu, lembar wawancara untuk responden yang terpilih.

Teknik analisis data pada penelitian ini menggunakan teknik deskriptif kualitatif. Data disajikan dalam bentuk tabel, kemudian data hasil wawancara tersebut dikelompokan (jenis, genus, bagian yang dimanfaatkan, cara meramu, dan cara penggunaan/pemakaian sebagai obat/ramuan tradisional (dioleskan, dimakan/minum dan lain-lain)

\section{HASIL DAN PEMBAHASAN}

Data demografi pasien dari 250 orang responden untuk jenis kelamin sebagian besar $(80 \%)$ adalah perempuan dan $20 \%$ adalah laki-laki (tabel 1). Pada umunya perempuan lebih aktif dibandingkan dengan lakilaki dalam hal merawat kesehatan keluarganya selain itu, wanita juga lebih aktif dalam meramu tanamanan sebagai obat tradisional jika diantara anggota keluarganya ada yang sakit atau untuk menjaga kesehatan tubuh.

Dari umur responden adalah kisaran umur lebih dari 45 tahun dan yang paling sedikit adalah 25 Tahun. Hal ini dipengaruhi oleh responden 
H Khuluq, N Zukhruf, T Cahyani, A Stefani, L Fitriyati, K Majidah, B Dwi \& J Yuliana / Jurnal Kesehatan 14 (1) 2021, 59-67

dengan usia lebih tua yang lebih. banyak menggunakan tanaman obat karena sudah percaya dan terbiasa yang dilakukan secara turun temurun, sedangkan pada umumnya generasi muda hanya akan percaya dan menggunakan tumbuhan obat setelah

membuktikan khasiatnya sendiri. Selain itu, semakin pesatnya perkembangan ilmu dan fasilitas kesehatan juga menyebabkan menurunnya tingkat minat generasi muda terhadap pemanfaatan tanaman sebagai obat tradisional (Zaman, 2009).

Tabel 1. Deskriptif Subjek Penelitian

\begin{tabular}{cll}
\hline Jenis Kelamin & Frekuensi & Persentase (\%) \\
\hline Laki-laki & 50 & $20.0 \%$ \\
Perempuan & 200 & $80.0 \%$ \\
\hline Usia & Frekuensi & Persentase \% \\
\hline <25 Tahun & 9 & $3.6 \%$ \\
26-35 Tahun & 30 & $12.0 \%$ \\
36-45 Tahun & 45 & $18.0 \%$ \\
45-55 Tahun & 83 & $33.2 \%$ \\
<55 Tahun & 83 & $33.2 \%$ \\
\hline Pendidikan Terakhir & Frekuensi & Presentase \\
\hline SD & 117 & $46.8 \%$ \\
SMP & 53 & $21.2 \%$ \\
SMA & 60 & $24.0 \%$ \\
D3 & 4 & $1.6 \%$ \\
S1-S2 & 9 & $3.6 \%$ \\
Lain-lain & 7 & $2.8 \%$ \\
\hline Pekerjaan & Frekuensi & Persentase \% \\
\hline Petani & 58 & $23.2 \%$ \\
Pedagang & 54 & $21.6 \%$ \\
Wiraswasta & 32 & $12.8 \%$ \\
PNS & 7 & $2.8 \%$ \\
Pensiun & 4 & $1.6 \%$ \\
IRT & 90 & $36.0 \%$ \\
Tukang Pijat (Dukun) & 5 & $2.0 \%$ \\
\hline Penghasilan & Frekuensi & Persentase \% \\
\hline Rp. 0-1.400.000 & 170 & $68.0 \%$ \\
Rp. 1.400.000-3.000.000 & 62 & $24.8 \%$ \\
Rp. 3.000.000-6.000.000 & 16 & $6.4 \%$ \\
Rp. > 6.000.000 & 2 & $0.8 \%$ \\
\hline & &
\end{tabular}

Tingkat pendidikan subjek penelitian menunjukan bahwa pengguna tanaman obat yang paling banyak yaitu masyarakat yang pendidikan terkhirnya adalah Sekolah Dasar (SD) sebesar (46.8\%) Sedangkan pengguna yang paling sedikit.adalah responden dengan pendidikan D3 (1.6\%) (Tabel 1).
Hal ini sinkron dengan data usia, dimana kelompok masyarakat yang punya akses ke media cenderung tidak menggunakan tanaman obat (usia muda dan pendidikan tinggi) dibanding kelompok masyarakat usia lanjut dan pendidikan rendah. Data mata pencaharian menunjukkan bahwa sebagian besar responden adalah petani yaitu $58 \%$. Hal ini erat kaitannya 
karena pekerjaan mereka sehari hari sangat mempermudah memanfaatkan tumbuhan obat baik yang tumbuh liar maupun yang dibudidayakan sendiri. Untuk data penghasilan sebagian besar yaitu $68 \%$ adalah dibawah 1,4 juta atau penghasilan rendah, hal ini sesuai dengan data sebelumnya bahwa sebagian besar responden adalah petani, pendidikan rendah. Ditemukan
20 tanaman obat yang dimanfaatkan masyarakat di 5 kecamatan diwalayah kabupaten Kebumen (Tabel 2). Mahoni (Divya et al., 2012) belum banyak diteliti efek antihipertensinya. Demikian juga mangkokan belum dilakukan penelitian sebagai antihipertensi (Moghadamtousi et al., 2013).

Tabel 2. Tanaman Obat Hipertensi

\begin{tabular}{llllll}
\hline No & Nama tanaman & Spesies & Bagian & Cara Olah & Cara Pakai \\
\hline 1 & Seledri & Apium graveolens & Daun & Ditumbuk, diseduh & Diminum \\
2 & Mangkokan & Polyscias scutellaria & Daun & Direbus & Diminum \\
3 & Mentimun & Cucumis sativus $L$ & Buah & tanpa pengolahan & Dimakan \\
4 & Labu Siam & Sechium edule & Buah & dikukus & Dimakan \\
5 & Kersen & Muntinga calabura L & Daun & direbus & Diminum \\
6 & Bawang Putih & Allium sativum & Umbi & Ditumbuk, Diremas & Diminum, \\
& & & & Dimakan \\
7 & Rosella & Hibiscus sabdariffa & Bunga & diseduh & Diminum \\
8 & Mahoni & Switenia mahagoni & Biji & Direbus & Diminum \\
9 & Kelor & Moringa oleifera L & Daun & direbus & Diminum \\
10 & Salam & Syzygium polyanthum & Daun & direbus & Diminum \\
11 & Belimbing & Averrhoa bilimbi L & Buah & Direbus & Tanpa \\
& Wuluh & & & & pengolahan \\
12 & Delima & Punica granatum & Buah & Langsung & Diminum \\
13 & Akar Alang- & Imperata cylindrica & Akar & Direbus & Diminum \\
& alang & (L.) Raeusch. & & & \\
14 & Jinten hitam & Nigella sativa & Biji & Direbus & Diminum \\
15 & Mengkudu & Morinda citrifolia & Daun & Direbus & Diminum \\
16 & Ciplukan & Physalis angulate $L$ & Duah & direbus & Diminum \\
17 & Kumis Kucing & Orthosiphon aristatus & daun & direbus & Diminum \\
18 & Sirsak & Annona muricata L & daun & direbus & Diminum \\
19 & Sereh & Piper betle $(L)$ & Daun & Direbus, ditumbuk & Diminum \\
20 & Ubi Jalar & Ipomoea batatas $L$ & Daun & direbus & Diminum \\
\hline & & & &
\end{tabular}

Mentimun sudah cukup tahap uji pre klinik (Ali et al., 2016). banyak dilakukan percobaan klinik Labu siam selain dikenal sebagai sayuran mempunyai efek sebagai yang dikonsumsi juga dimanfaatkan antihipertensi (Rushda Saeedi 1, sebagai obat hipertensi tapi masih dalam 2020)(Pertami et al., 2017)(Sudiana tahap uji pre klinik (Vela-g, 2017) Kersen I ketut, Ira Suarilah, 2008) dalam tahap uji pre klinik (Mahmood et mentimun juga berefek sebagai al., 2014). Jintem hitam sudah banyak diuretik dan sudah diteliti bisa dilakukan dilakukan uji klinik (Ahmad et menurunkan tekanan darah. Daun al., 2013). Delima sudah dilakukan uji salam sudah diteliti sebagai obat klinik tahap awal (Asgary et al., 2013) hipertensi hanya sampai pada uji pre Ciplukan masih dalam tahap uji pre klinik klinik (Ismail \& Wan Ahmad, (ishak, 2019) Belimbing wuluh masih 2019). Mengkudu juga masih dalam dalam tahap uji pre klinik(Soncini et al., 
H Khuluq, N Zukhruf, T Cahyani, A Stefani, L Fitriyati, K Majidah, B Dwi \& J Yuliana / Jurnal Kesehatan 14 (1) 2021, 59-67

2011)(uswatun Hasanah Linnisaa, 2014) Bawang putih sudah dilakukan banyak dilakukan uji klinik (Ashraf et al., 2013) Alangalang sudah dilakukan uji pre klinik (Ruslin et al., 2013) Bunga Rosella sudah dilakukan uji klinik untuk hipertensi

(Ritonga, 2017)(AbdelRahman \& Shayoub, 2016) ; demikian juga seledri sudah dilakukan uji klinik untuk hipertensi (Marsita, 2019) (Kooti et al., 2014). Ubi jalar sudah banyak dilakukan uji pre klinik tetapi efek antihipertensi belum pernah di uji preklinik (Panda \& Sonkamble, 2012). Kelor masih dalam uji pre klinik (Fahey, 2017). Dari cara menyiapkan sebagian besar $(65 \%)$ adalah dengan cara direbus (Tabel 3). Cara penggunaan sebagian besar diminum (tabel 4) yaitu $80 \%$, dan bagian yang paling banyak digunakan yaitu daun (tabel 5) sebanyak 50\%. Hal ini sama dengan penelitian lain yang dilakukan Astri di Kabupaten Sanggau (Astria et al., 2011)

Tabel 3. Cara Menyiapkan

\begin{tabular}{llcc}
\hline No & Cara Pakai & Frekuensi & $\begin{array}{c}\text { Persentase } \\
\%\end{array}$ \\
\hline 1 & Dikukus & 1 & 5 \\
2 & Direbus & 13 & 65 \\
3 & Direbus, & & \\
& ditumbuk & 1 & 5 \\
4 & diseduh & 1 & 5 \\
5 & Ditumbuk, & & \\
& Diremas & 1 & 5 \\
6 & Ditumbuk, & 1 & 5 \\
\hline
\end{tabular}

\begin{tabular}{llll}
\hline & diseduh & & \\
7 & Langsung & 1 & 5 \\
8 & Tanpa & & \\
& Pengolahan & 1 & 5 \\
\hline
\end{tabular}

Tabel 4. Cara Penggunaan

\begin{tabular}{llcc}
\hline No & Cara Penggunaan & Frekuensi & $\begin{array}{c}\text { Persentase } \\
\%\end{array}$ \\
\hline 1 & Dimakan & 2 & 10 \\
2 & Diminum & 16 & 80 \\
3 & Diminum, & & 5 \\
& Dimakan & 1 & 5 \\
\hline
\end{tabular}

\begin{tabular}{llcc}
\hline \multicolumn{4}{c}{ Tabel 5. Bagian Yang Digunakan } \\
\hline No & $\begin{array}{c}\text { Bagian yang } \\
\text { digunakan }\end{array}$ & Frekuensi & Persentase \% \\
\hline 1 & Akar & 1 & 5 \\
2 & Biji & 2 & 10 \\
3 & Buah & 5 & 25 \\
4 & Bunga & 1 & 5 \\
5 & Daun & 10 & 50 \\
6 & Umbi & 1 & 5 \\
\hline
\end{tabular}

\section{KESIMPULAN}

Didapat 20 spesies tanaman obat yang berefek antihipertensi, dimana 1 spesies belum pernah dilakukan uji preklinik maupun klinik, 5 spesies sudah dilakukan uji klinik dan 15 baru tahap uji pre klinik.

\section{UCAPAN TERIMAKASIH}

Ucapan terimakasih kami sampaikan kepada LPPM Stikes Muhammadiyah Gombong

\section{DAFTAR PUSTAKA}

AbdelRahman, Z., \& Shayoub, M. E. H. (2016). Hibiscus Miracle in Treatment of Hypertension. American Journal of Pharmtech Research, 6(2), 293-310. https://doi.org/10.1109/4.848208

Ahmad, A., Husain, A., Mujeeb, M., Khan, S. A., Najmi, A. K., Siddique, N. A., Damanhouri, Z. A., \& Anwar, F. (2013). A review on therapeutic potential of Nigella sativa: A miracle herb. Asian Pacific Journal of Tropical Biomedicine, 3(5), 337-352. https://doi.org/10.1016/S2221-1691(13)60075-1 
H Khuluq, N Zukhruf, T Cahyani, A Stefani, L Fitriyati, K Majidah, B Dwi \& J Yuliana / Jurnal Kesehatan 14 (1) 2021, 59-67

Ali, M., Kenganora, M., \& Manjula, S. N. (2016). Health benefits of morinda citrifolia (Noni): A review. Pharmacognosy Journal, 8(4), 321-334. https://doi.org/10.5530/pj.2016.4.4

Asgary, S., Keshvari, M., Sahebkar, A., Hashemi, M., \& Rafieian-Kopaei, M. (2013). Clinical investigation of the acute effects of pomegranate juice on blood pressure and endothelial function in hypertensive individuals. ARYA Atherosclerosis, 9(6), 326-331. https://doi.org/10.22122/arya.v9i6.643

Ashraf, R., Khan, R. A., Ashraf, I., \& Qureshi, A. A. (2013). Effects of Allium sativum (Garlic) on systolic and diastolic blood pressure in patients with essential hypertension. Pakistan Journal of Pharmaceutical Sciences, 26(5), 859-863.

Astria, Budhi, S., \& Sisillia, L. (2011). Kajian Etnobotani Tumbuhan Obat Padamasyarakat Dusun Semoncol Kecamatan Balai Kabupaten Sanggau. 19.

Divya, K., Pradeep, H. R., Kumar, K. K., Hari, V. K. ., \& Jyothi, T. (2012). Herbal Drug Swietenia mahogany Jacq.: A Review. Global J Res. Med. Plants \& Indigen. Med, 1(10), 557-67.

E, S. (2017). etnomedisin obat malaria. 8-39.

Eko Atmojo, S. (2015). Pengenalan Etnobotani Pemanfaatan Tanaman Sebagai Obat Kepada Masyarakat Desa Cabak Jiken Kabupaten Blora. Jurnal Ilmiah WUNY, 15(1). https://doi.org/10.21831/jwuny.v15i1.3529

Fahey, J. W. (2017). Moringa oleifera: A review of the medicinal potential. Acta Horticulturae, 1158(March), https://doi.org/10.17660/ActaHortic.2017.1158.25

ishak, hasanuddin. (2019). Uji Aktivitas Antihipertensi Ekstrak Etanol Herba Ciplukan (Physalis Angulata L.) Terhadap Tikus Putih Jantan SpragueDawley Yang Diinduksi Prednison Dan Nacl, Skripsi, Fakultas Farmasi, Universitas Setia Budi, Surakarta. Studi. Society.

Ismail, A., \& Wan Ahmad, W. A. N. (2019). Syzygium polyanthum (Wight) Walp: A potential phytomedicine. Pharmacognosy Journal, 11(2), 429-438. https://doi.org/10.5530/pj.2019.11.67

S

Kemenkes. (2006). Pharmaceutical care hipertensi.

Kooti, W., Ali-akbari, S., Asadi-samani, M., Ghadery, H., \& Ashtary-larky, D. (2014). A review on medicinal plant of. Advanced Herbal Medicine, 1(1), $48-59$. 
H Khuluq, N Zukhruf, T Cahyani, A Stefani, L Fitriyati, K Majidah, B Dwi \& J Yuliana / Jurnal Kesehatan 14 (1) 2021, 59-67

Mahmood, N. D., Nasir, N. L. M., Rofiee, M. S., Tohid, S. F. M., Ching, S. M., Teh, L. K., Salleh, M. Z., \& Zakaria, Z. A. (2014). Muntingia calabura: A review of its traditional uses, chemical properties, and pharmacological observations. In Pharmaceutical Biology (Vol. 52, Issue 12). https://doi.org/10.3109/13880209.2014.908397

Marsita, E. (2019). Effect of Celery (Apium Graveolens) on The Reduction of Blood Pressure: A Systematic Review. 618-618. https://doi.org/10.26911/theicph.2019.05.17

Moghadamtousi, S. Z., Goh, B. H., Chan, C. K., Shabab, T., \& Kadir, H. A. (2013). Biological activities and phytochemicals of Swietenia macrophylla king. $\quad$ Molecules, 18(9), 10465-10483. https://doi.org/10.3390/molecules180910465

Panda, V., \& Sonkamble, M. (2012). Phytochemical constituents and pharmacological activities of Ipomoea batatas 1. ( Lam ) - A review. Int. J. Res. Phytochem. Pharmacol., 2(1), 25-34.

Pertami, S. B., Rahayu, D. Y. S., \& Budiono, B. (2017). Effect of Cucumber (Cucumis Sativus) Juice on Lowering Blood Pressure in Elderly. Public Health of Indonesia, 3(1), 30-36. https://doi.org/10.36685/phi.v3i1.93

Ritonga, N. (2017). Roselle Flower ( Hibiscus Sabdariffa ). Belitung Nursing Journal, 3(3), 229-237.

Rushda Saeedi 1, A. S. * 1 and K. R. 2. (2020). ETHNOMEDICINAL USES AND PHARMACOLOGICAL ACTIVITIES OF DIFFERENT PARTS OF CUCUMIS SATIVUS LINN: AN UPDATE. IEEE International Conference on Acoustics, Speech, and Signal Processing (ICASSP) 2017, 41(2), 84-93. https://doi.org/10.13040/IJPSR.0975-8232.11(4).1549-56

Ruslin, Asmawi, M. Z., Rianse, U., Sahidin, I., Dhianawaty, D., Soemardji, A. A., \& Amalia, L. (2013). Anti-hypertensive activity of Alang - Alang (Imperata cylindrica (L.) Beauv. root methanolic extract on male Wistar rat. International Journal of Research in Pharmaceutical Sciences, 4(4), 537542.

Soncini, R., Santiago, M. B., Orlandi, L., Moraes, G. O. I., Peloso, A. L. M., Dos Santos, M. H., Alves-Da-Silva, G., Paffaro, V. A., Bento, A. C., \& GiustiPaiva, A. (2011). Hypotensive effect of aqueous extract of Averrhoa carambola L. (Oxalidaceae) in rats: An in vivo and in vitro approach. Journal of Ethnopharmacology, 133(2), 353-357. https://doi.org/10.1016/j.jep.2010.10.001 
H Khuluq, N Zukhruf, T Cahyani, A Stefani, L Fitriyati, K Majidah, B Dwi \& J Yuliana / Jurnal Kesehatan 14 (1) 2021, 59-67

Sudiana I ketut, Ira Suarilah, R. (2008). Cucumber Juice Decrease Blood Pressure on Essensial Hypertension Patient. Fakultas Keperawatan Universitas Airlangga, 2(1), 20-25.

Tapundu, A. S., Anam, S., \& Pitopang, R. (2015). Studi Etnobotani Tumbuhan Obat Pada Suku Seko Di Desa Tanah Harapan, Kabupaten Sigi, Sulawesi Tengah. Jurnal Biocelebes, 9(92), 66-86.

uswatun Hasanah Linnisaa, susi endra wati. (2014). Elixir Of Extract Leaf Belimbing Wuluh (Averrhoa Bilimbi L.) As Anti Hypertension With Method Of Maserasi. 1(1), 51-55.

Vela-g, G. (2017). Chayote ( Sechium edule ) Phytochemical and pharmacological approaches. November.

Zaman, M. Q. (2009). Etnobotani tumbuhan obat di kabupaten pamekasan-madura provinsi Jawa Timur. 1-111. https://doi.org/10.1128/AEM.02093-09 